\title{
ANALISIS VARIANS MULTIVARIAT PADA EKSPERIMEN DENGAN RANCANGAN ACAK LENGKAP
} (Variance Multivariat Analysis for Experiment with Complete Random Design)

\section{Th. PENTURY}

Jurusan Matematika FMIPA Universitas Pattimura Ambon

Jl. Ir. M. Putuhena, Kampus Unpatti, Poka-Ambon

\begin{abstract}
ABSTRAK
Metode Statistika Multivariat adalah teknik analisis statistik yang memperlakukan sekumpulan variabel dependent yang saling berhubungan sebagai satu sistem, dengan memperhitungkan kuatnya hubungan antar variabel-variabel tersebut. Analisis yang demikian biasanya dikenal atau disebut Analisis Statistik Multivariat atau disingkat Analisis Multivariat.

Tujuan analisis dengan metode ini adalah menemukan dan menafsirkan struktur yang mendasari data. Pada analisis ini data yang diolah adalah data dari hasil pengukuran beberapa variabel tak bebas dan dapat saja ditambah dengan hasil pengukuran dari satu atau beberapa variabel bebas. Dengan demikian yang diukur adalah satu atau beberapa kelompok variabel, sedang datanya adalah beberapa kelompok skor.

Analisis Varians adalah tehnik analisis statistik, yang biasanya digunakan untuk komparasi beberapa rata-rata populasi, berdasarkan perbandingan pasangan taksiran varians faktor-faktor tertentu. Pada kondisi multivariat, dimana analisis ini merupakan perluasan atau generalisasi dari analisis varians adalah Analisis Varians Multivariat, dan merupakan tehnik analisis data tentang perbedaan pengaruh beberapa variabel terhadap sekelompok variabel kriteria.
\end{abstract}

Kata Kunci: Statistik Uji Wilks, Matriks Varian Kovarians

\section{PENDAHULUAN}

Analisis Varians adalah teknik analisis statistik, yang biasanya digunakan untuk komparasi beberapa rata-rata populasi, berdasarkan perbandingan pasangan taksiran varians faktor-faktor tertentu. Pada kondisi multivariat, dimana analisis ini merupakan perluasan atau generalisasi dari analisis varians adalah Analisis Varians Multivariat, dan merupakan tehnik analisis data tentang perbedaan pengaruh beberapa variabel terhadap sekelompok variabel kriteria.

Pada Analisis Varians Univariat, keputusan yang dibuat terhadap hipotesis yang diajukan didasarkan pada satu statistik uji yaitu statistik F dari Fisher, dimana nilai statistik ini ditentukan oleh rasio dari dua rata-rata Jumlah Kuadrat. Pada Analisis Varians Multivariat ada beberapa statistik uji yang dapat digunakan untuk membuat keputusan terhadap hipotesis yang diajukan. Dalam tulisan ini akan dijelaskan statistik uji yang digunakan untuk beberapa rancangan eksperimen yang biasanya digunakan.

Ada empat statistik uji yang biasanya digunakan untuk menjastifikasi hipotesis yang digunakan masing-masing adalah

1. Uji hasil bagi kemungkinan, dengan menggunakan statistik uji $\lambda$ ( lambda) dari Wilks. Notasi yang digunakan adalah $\mathrm{U}$ (dari distribusi Uniform)

$$
U=\frac{|(J K G)|}{\left[(J K G)+\left(J K P_{r}\right)\right]}
$$

dimana

JKG = Jumlah Kuadrat Galat ( Matriks varianskovarians Galat)
JKPr = Jumlah Kuadrat Perlakuan (Matriks varianskovarians Perlakuan)

2. Uji Telusur dari Lawley-Hotelling dengan statistik LH notasi yang digunakan adalah

$$
\mathrm{LH}=(\mathrm{JKG})^{-1}(\mathrm{JK} \text { Pr })
$$

dimana $(\mathrm{JKG})^{-1}$ adalah invers dari matriks varianskovarians galat. JK Pr adalah matriks varians-kovarians perlakuan.

3. Uji Akar Maksimum dari Roy, dengan statistik uji R (akar karakteristik maksimum) notasi yang digunakan adalah

$$
\mathrm{R}=(\mathrm{JKG})^{-1}(\mathrm{JK} \mathrm{Pr})
$$

dimana $(\mathrm{JKG})^{-1}$ adalah invers dari matriks varianskovarians galat. JK Pr adalah matriks varians-kovarians perlakuan.

4. Uji Pillai, dengan statistik uji P yang dinotasikan dengan bentuk

$$
P=\sum_{i=1}^{n}\left(\frac{k_{i}}{1+k_{i}}\right)
$$

dimana $\mathrm{k}_{1}, \mathrm{k}_{2}, \ldots, \mathrm{k}_{\mathrm{n}}$ adalah akar-akar karakteristik dari $(\mathrm{JKG})^{-1}$

Statistik Wilks lambda $(\lambda)$ dengan notasi $U$ memiliki beberapa sifat yang perlu diketahui dan sangat penting untuk melakukan pengujian dengan statistik uji ini. Sifat ini digunakan untuk mempermudah analisis atau memberi pilihan yang cukup memudahkan pekerjaan. Sifat-sifat ini adalah sebagai berikut :

1. Distribusi U dengan derajad kebebasan (p;m;n) sama dengan distribusi $U$ yang berderajat kebebasan (m;p;n;+m - p); 
2. Untuk $\mathrm{p}=2$ nilai $\mathrm{U}_{\mathrm{p} ; \mathrm{m} ; \mathrm{n}}$ dapat ditransformasi ke nilai $\mathrm{F}$ dengan rumus

$$
\frac{(n-1)\left(1-\sqrt{U_{2 ; m ; n}}\right)}{m \sqrt{U_{2 ; m ; n}}}=F_{2 m ; 2(n-1)}
$$

Dimana $\mathrm{U}_{2 ; \mathrm{m} ; n}$ menyatakan nilai variabel acak yang berdistribusi $U$ dengan derajat kebebasan (2; $m$; $n$ ), sedang $\mathrm{F}_{2 \mathrm{~m} ;} 2$ (n-1) menyatakan nilai variabel acak yang berdistribusi F dengan derajat kebebasan [ $2 \mathrm{~m}$; $(2 \mathrm{n}-2)$ ].

3. $\frac{(n-p+1)(1-\sqrt{U p ; 2 ; n})}{p \sqrt{U_{p ; 2 ; n}}}=F_{2 p ; 2(n-p+1)}$

4. $\frac{(n)\left(1-U_{1 ; m ; n}\right)}{m\left(U_{1 ; m ; n}\right)}=F_{m ; n}$

$$
\frac{(n-p+1)\left(1-U_{p ; 1 ; n}\right)}{p\left(U_{p ; 1 ; n}\right)}=F_{p ; n-p+1}
$$

\section{Manova pada Rancangan Acak Lengkap}

Untuk membandingkan efek dari t perlakuan, yaitu $\mathrm{P}_{1}$, $\mathrm{P}_{2}, \ldots, \mathrm{P}_{\mathrm{t}}$, maka perlakuan-perlakuan itu perlu dikenakan secara acak pada $\mathrm{t}$ kelompok, dimana masing-masing kelompok merupakan sampel acak dari populasi yang diteliti. Untuk memudahkan penunjukan, kelompok yang dikenai atau mengalami perlakuan $\mathrm{P}_{\mathrm{i}}$ maka disebutkan dengan kelompok ke-i, sedang populasi yang bersangkutan disebut populasi ke-i, dimana $\mathrm{i}=1,2, \ldots$, dan seterusnya.

Andaikan perlakuan itu telah dikenakan menurut rancangan yang digunakan, dimana kelompok ke-i terdiri atas $n_{i}$ subjek. Selanjutnya untuk mengukur efek perlakuan maka setiap subjek diukur p variabelnya, yaitu $\mathrm{X}_{1}, \mathrm{X}_{2}, \ldots ., \mathrm{X}_{\mathrm{p}}$. Model seperti ini dikenal sebagai model Rancangan Acak Lengkap. Data yang diperoleh dari

\begin{tabular}{|c|c|c|c|c|}
\hline & \multicolumn{4}{|c|}{ Perlakuan } \\
\hline & $\mathrm{P}_{1}$ & $\mathrm{P}_{2}$ & $\ldots$ & $\mathrm{P}_{\mathrm{t}}$ \\
\hline Skor & $\begin{array}{cccc}\mathrm{X}_{111} & \mathrm{X}_{112} & \ldots & \mathrm{X}_{11 \mathrm{p}} \\
\mathrm{X}_{211} & \mathrm{X}_{212} & \ldots & \mathrm{X}_{21 \mathrm{p}} \\
\cdot & & & \\
\cdot & & & \\
\cdot & & & \\
\cdot & & & \\
\mathrm{X} \mathrm{n}_{1} 11 & \mathrm{Xn}_{1} 12 & \mathrm{Xn}_{1} 1 \mathrm{p}\end{array}$ & $\begin{array}{cccc}\mathrm{X}_{121} & \mathrm{X}_{122} & \ldots & \mathrm{X}_{12 \mathrm{p}} \\
\mathrm{X}_{221} & \mathrm{X}_{222} & \ldots & \mathrm{X}_{22 \mathrm{p}} \\
\cdot & & & \\
\cdot & & & \\
\cdot & & & \\
\cdot & & & \\
\cdot & & & \\
& & & \\
\mathrm{X} \mathrm{n}_{2} 21 & \mathrm{Xn}_{2} 22 & \mathrm{Xn}_{2} 2 \mathrm{p}\end{array}$ & $\begin{array}{l}\ldots \\
\ldots \\
\cdots \\
\cdots \\
\cdots \\
\cdots\end{array}$ & $\begin{array}{cc}\mathrm{X}_{1 \mathrm{tl}} & \mathrm{X}_{1 \mathrm{t2} 2} \\
\mathrm{X}_{2 \mathrm{tl}} & \mathrm{X}_{2 \mathrm{t2} 2}\end{array}$ \\
\hline Jumlah & $X_{.11} X_{.12} \ldots X_{.1 p}$ & $\mathbf{X}_{.21} \mathbf{X}_{.22} \ldots \mathbf{X}_{.2 \mathrm{p}}$ & $\ldots$ & $X_{. t 1} X_{. t 2} .$. \\
\hline
\end{tabular}
pengukuran ini dapat disusun sebagai berikut :
Selanjutnya digunakan notasi-notasi sbb :

$\mathrm{X}_{\mathrm{ijk}}=$ skor subjek ke-i dari kelompok ke-j, (yaitu kelompok yang mendapat perlakuan $\mathrm{P}_{\mathrm{j}}$ ), pada variabel $\mathrm{X}_{\mathrm{k}}$. $\mathrm{i}=1,2,3, \ldots, \mathrm{nj}$;

$\mathrm{j}=1,2,3, \ldots, \mathrm{t}$;

$\mathrm{k}=1,2,3, \ldots, \mathrm{p}$.

$$
\begin{aligned}
X_{. j k} & =\sum_{i=1}^{n_{j}} X_{i j k} \\
\bar{X}_{. j k} & =\frac{1}{n_{j}} \sum_{i=1}^{n_{j}} X_{i j k}=\frac{1}{n_{j}}\left(X_{. j k}\right)
\end{aligned}
$$

$\mu_{\text {.jk }}=$ rerata dari populasi ke-j untuk variabel $X_{\mathrm{k}}$

$$
\bar{X}_{. . k}=\frac{X_{.1 k}+X_{.2 k}+\ldots+X_{. t k}}{n_{1}+n_{2}+\ldots+n_{t}}
$$

$$
\begin{aligned}
& x=\left(\begin{array}{l}
x_{1} \\
x_{2} \\
\cdot \\
\cdot \\
\cdot \\
x_{p}
\end{array}\right) \quad x=\left(\begin{array}{l}
\bar{x}_{. j 1} \\
\bar{x}_{. j 2} \\
\cdot \\
\cdot \\
\cdot \\
\bar{x}_{. j p}
\end{array}\right) \quad \bar{x}_{. .}=\left(\begin{array}{l}
\bar{x}_{. .1} \\
\bar{x}_{. .2} \\
\cdot \\
\cdot \\
\cdot \\
\bar{x}_{. . p}
\end{array}\right) \quad \mu_{j}=\left(\begin{array}{l}
\bar{x}_{. j 1} \\
\bar{x}_{. j 2} \\
\cdot \\
\cdot \\
\cdot \\
\bar{x}_{. j p}
\end{array}\right) \\
& \text {, untuk } \mathrm{i}=1,2, \ldots, \mathrm{n}_{\mathrm{j}} \text {; } \\
& x_{i j}=\left(\begin{array}{l}
x_{i j 1} \\
x_{i j 2} \\
\cdot \\
\cdot \\
x_{i j p}
\end{array}\right)
\end{aligned}
$$


Pada kondisi univariat, untuk menguji kesamaan ratarata populasi perlu dihitung jumlah-jumlah kuadrat, yaitu jumlah Kuadrat untuk Perlakuan, JKPr, dan Jumlah Kuadrat untuk Galat JKG. Pada analisis varians multivariat kita juga akan menguji kesamaan vektor ratarata, sehingga diperlukan atau harus ditentukan matriks Jumlah Kuadrat dan Hasil Silang (JKHS), baik untuk perlakuan maupun untuk galat yang dikenal dengan JKHS Perlakuan dan JKHS galat. Perhitungannya adalah sebagai berikut :

$$
\begin{aligned}
\mathrm{JK}(\text { Tot }) & =\mathrm{JKHS} \\
& =\sum_{\mathrm{j}=1}^{\mathrm{t}} \sum_{\mathrm{i}=1}^{\mathrm{n}_{\mathrm{j}}}\left(\mathrm{x}_{\mathrm{ij}}-\mathrm{x}_{. .}\right)\left(\mathrm{x}_{\mathrm{ij}}-\mathrm{x}_{. .}\right)^{\prime} \\
& \left.=\sum \sum \begin{array}{c}
\mathrm{x}_{\mathrm{ij}} \mathrm{x}_{\mathrm{ij}}^{\prime}-\mathrm{n} \mathrm{x}_{. .} \mathrm{x}^{\prime} . . \\
\mathrm{x}_{\mathrm{ij} 2} \\
\cdot \\
\cdot \\
\mathrm{x}_{\mathrm{ijp}}
\end{array}\right] \quad\left(\mathrm{x}_{\mathrm{ij} 1}, \mathrm{x}_{\mathrm{ij} 2}, \ldots, \mathrm{x}_{\mathrm{ijp}}\right)
\end{aligned}
$$

dimana $n=n_{1}+n_{2}+\ldots+n_{t}$.

JK $($ Pr $)=$ JKHS Perlakuan

$$
\begin{aligned}
& =\sum_{j=1}^{t} n_{j} \quad \bar{x}_{. j} \bar{x}_{. j}^{\prime}-n_{\bar{x}} . . \bar{x}_{. .}^{\prime} \\
& =\sum n_{j}\left[\begin{array}{c}
\bar{x}_{. j 1} \\
\bar{x} . j 2 \\
\cdot \\
\vdots \\
\bar{x} . j p
\end{array}\right] \quad\left(\bar{x}_{. j 1}, \bar{x}_{. j 2}, \ldots, \bar{x}_{. j p}\right) \\
& -n \quad\left[\begin{array}{c}
\bar{x}_{. .1} \\
\bar{x} . .2 \\
\cdot \\
\cdot \\
\bar{x}_{. . p}
\end{array}\right] \quad\left(\bar{x}_{. .1}, \bar{x}_{. .2}, \ldots, \bar{x}_{. . p}\right)
\end{aligned}
$$

$$
\begin{aligned}
\mathrm{JKG} & =\mathrm{JKHS} \text { Galat } \\
& =\mathrm{JK}(\text { Tot })-\mathrm{JK}\left(\mathrm{P}_{\mathrm{r}}\right)
\end{aligned}
$$

Apabila vektor rata-rata $\mathrm{t}$ populasi itu sama, maka variabel $\frac{|(J K G)|}{\left[(J K G)+\left(J K P_{r}\right)\right]}$ akan berdistribusi U dengan derajat kebebasan (p; t-1 ; n-t). Sifat terakhir ini dapat digunakan untuk menguji hipotesis kesamaan vektor ratarata populasi.

Pada kondisi univariat, apabila $\mathrm{p}=1$ maka untuk menguji kesamaan rata-rata populasi digunakan statistik uji

$$
F=\frac{R J K\left(P_{r}\right)}{R J K G}
$$

Dalam pengujian ini hipotesis nol $\left(\mathrm{H}_{0}\right)$ yang diajukan adalah bahwa rata-rata populasi sama, akan ditolak pada taraf signifikansi $\alpha$ tertentu jika $\mathrm{F}_{\text {hit }}>\mathrm{F}_{\text {tab }}$ dengan derajat kebebasan $(\mathrm{t}-1 ; \mathrm{n}-\mathrm{t})$. Hal ini berarti bahwa bila Ho ditolak maka akan ada dua kemungkinan yaitu RJK $\left(\mathrm{P}_{\mathrm{r}}\right)$ yang terlalu besar, atau RJK (G) terlalu kecil.

Dengan demikian pada kondisi multivariat, hipotesis nol $\left(\mathrm{H}_{0}\right)$ bahwa vektor rata-rata $\mathrm{t}$ populasi sama, maka akan terjadi $\mathrm{H}_{\mathrm{o}}$ ditolak jika $|\mathrm{JK}(\mathrm{G})|$ terlalu kecil. Sehingga untuk $\mathrm{H}_{\mathrm{o}}=\mu_{1}=\mu_{2}==\mu_{\mathrm{t}}$, kriteria keputusannya ialah Ho ditolak pada taraf signifikansi $\alpha$ tertentu jika

$$
\frac{|(J K G)|}{\left[(J K G)+\left(J K P_{r}\right)\right]}<U_{\alpha} ;(p ; t-1 ; n-t)
$$

Pada analisis varians multivariat kondisinya hampir sama dengan analisis varians univariat, dimana pada situasi multivariat tersebut, tehnik analisis tadi hanya berlaku apabila pada setiap populasi, vektor variabel $\mathrm{X}$ berdistribusi Normal p-variat, dengan matriks varianskovarians yang sama. Berikut ini disajikan sebuah contoh untuk memperkenalkan analisis varians multivariat.

Pada sebuah penelitian pertanian dicobakan empat varietas tanaman jenis tertentu dalam 20 petak tanah, dimana tiap varietas ditaburkan secara acak pada lima petak. Setelah masa tanam 10 minggu diukur tinggi tanaman yang tumbuh $\left(\mathrm{X}_{1}\right)$ dan banyaknya cabang atau tunas $\left(\mathrm{X}_{2}\right)$ pada tiap batang tanaman. Data hasil pengukuran disajikan dalam tabel berikut :

Tabel 2. Data Hasil Percobaan

\begin{tabular}{|c|c|c|c|c|c|c|c|}
\hline \multicolumn{7}{|c|}{ Jenis Varietas } \\
\hline \multicolumn{2}{|c|}{$\mathbf{V}_{\mathbf{1}}$} & \multicolumn{2}{|c|}{$\mathbf{V}_{\mathbf{2}}$} & \multicolumn{2}{c|}{$\mathbf{V}_{\mathbf{3}}$} & \multicolumn{2}{c|}{$\mathbf{V}_{\mathbf{4}}$} \\
\hline $\mathbf{x}_{\mathbf{1}}$ & $\mathbf{x}_{\mathbf{2}}$ & $\mathbf{x}_{\mathbf{1}}$ & $\mathbf{x}_{\mathbf{2}}$ & $\mathbf{x}_{\mathbf{1}}$ & $\mathbf{x}_{\mathbf{2}}$ & $\mathbf{x}_{\mathbf{1}}$ & $\mathbf{x}_{\mathbf{2}}$ \\
\hline 58 & 4 & 49 & 7 & 54 & 6 & 58 & 4 \\
\hline 62 & 6 & 55 & 6 & 52 & 6 & 55 & 4 \\
\hline 60 & 7 & 48 & 4 & 51 & 7 & 51 & 5 \\
\hline 54 & 6 & 52 & 4 & 58 & 5 & 49 & 6 \\
\hline 58 & 6 & 49 & 7 & 61 & 6 & 52 & 4 \\
\hline
\end{tabular}

Untuk permasalahan diatas, hipotesis yang diajukan adalah:

$\mathrm{H}_{0}$ : Keempat vektor rata-rata populasi tidak berbeda, dalam notasi ditulis sebagai berikut

$\left[\begin{array}{l}\mu_{11} \\ \mu_{12}\end{array}\right]=\left[\begin{array}{l}\mu_{21} \\ \mu_{22}\end{array}\right]=\left[\begin{array}{l}\mu_{31} \\ \mu_{32}\end{array}\right]=\left[\begin{array}{l}\mu_{41} \\ \mu_{42}\end{array}\right]$

$\mathrm{H}_{1}$ : Paling sedikit ada satu pasangan vektor rata-rata populasi yang berbeda. 
Dengan menggunakan statistik uji wilks

$$
U=\frac{|(J K G)|}{\left[(J K G)+\left(J K P_{r}\right)\right]}
$$

dengan derajat bebas $(2 ; 3 ; 16)$, maka keputusan terhadapap hipotesis yang diajukan didasarkan pada kriteria sebagai berikut

$\mathrm{H}_{0}$ ditolak jika $\mathrm{U}_{\text {hit }}<\mathrm{U}_{\text {tab }}(2 ; 3 ; 16)$ dengan $\alpha=0.05$

$\mathrm{H}_{0}$ diterima jika $\mathrm{U}_{\text {hit }} \geq \mathrm{U}_{\text {tab }}(2 ; 3 ; 16)$ dengan $\alpha=0.05$

Dari data pada tabel 2 maka dengan menggunakan aturanaturan perhitungan dapat dilakukan analisis untuk menguji hipotesis yang telah diajukan. Hasil perhitungan adalah sebagai berikut :

$$
\begin{aligned}
& \mathrm{x}_{.11}=292 \quad \mathrm{x}_{.21}=253 \quad \mathrm{x}_{.31}=276 \quad \mathrm{x}_{.41}=265
\end{aligned}
$$

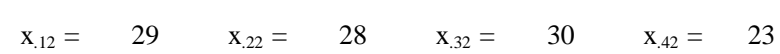

$$
\begin{aligned}
& X_{.11}=1 / 4(292+253+276+265)=271,5 \\
& x_{.2}=1 / 4(29+28+30+23)=37,5 \\
& \bar{x}=\left(\begin{array}{l}
x_{1} \\
x_{2}
\end{array}\right) ; \bar{x}_{. .}=\left(\begin{array}{c}
271,5 \\
37,5
\end{array}\right) \\
& \bar{x}_{.1}=\left(\begin{array}{c}
58,4 \\
5,8
\end{array}\right) ; \bar{x}_{.2}=\left(\begin{array}{c}
50,6 \\
5,6
\end{array}\right) \\
& \bar{x}_{.3}=\left(\begin{array}{c}
55,2 \\
6,0
\end{array}\right) \bar{x}_{.4}=\left(\begin{array}{c}
53,0 \\
4,6
\end{array}\right)
\end{aligned}
$$$$
J K t o t=\sum \sum x_{i j} x_{i j}^{\prime}-n x . . x^{\prime} . .=\left(\begin{array}{cc}
354,2 & -3,0 \\
-3,0 & 25,0
\end{array}\right)
$$$$
J K\left(P_{r}\right)=\sum n_{j} \bar{X}_{. j} \bar{X}_{. j}^{\prime}-n \bar{X}_{. .} \bar{X}_{. .}^{\prime}=\left(\begin{array}{cc}
165,0 & 12,4 \\
12,4 & 5,8
\end{array}\right)
$$$$
J K G=J K t o t-J K P_{r}=\left(\begin{array}{cc}
189,2 & -15,4 \\
-15,4 & 19.2
\end{array}\right)
$$$$
|J K G|=189,2 \times 19,2-(15,4)^{2}=3395,48
$$$$
|J K G+J K P|=354,2 \times 25-9=8846
$$$$
U=\frac{|(J K G)|}{\left[(J K G)+\left(J K P_{r}\right)\right]}=\frac{3395,48}{8846}=0,3838 \text { untuk } \mathrm{p}=2
$$

Tabel 3. Ringkasan Analisis Varians Multivariat

\begin{tabular}{|l|c|c|c|c|}
\hline $\begin{array}{c}\text { Sumber } \\
\text { Variasi }\end{array}$ & $\mathrm{db}$ & JKHS & $\mathrm{U}_{\mathrm{p} ; \mathrm{m} ; \mathrm{n}}$ & (p;m;n) \\
\hline Perlakuan & 3 & $\left(\begin{array}{cc}165.0 & 12,4 \\
12,4 & 5,8\end{array}\right)$ & 0,3838 & $(2 ; 3 ; 16)$ \\
\hline Galat & 16 & $\left(\begin{array}{cc}165,0 & -15,4 \\
-15,, 4 & 19,2\end{array}\right)$ & & \\
\hline Total & 19 & $\left(\begin{array}{cc}345,2 & -3,0 \\
-3,0 & 25,0\end{array}\right)$ & & \\
\hline
\end{tabular}

Karena $\mathrm{U}_{\text {hit }}=3,071<\mathrm{U}_{\text {tab (2;3;16) }}$ dengan $\alpha=0.05$ maka $\mathrm{H}_{0}$ ditolak.

Interval keyakinan suatu kontras atau kombinasi linear dari rata-rata populasi dapat dicari dengan pendekatan sebagi berikut :

Apabila

$$
a=\left(\begin{array}{l}
a_{1} \\
a_{2} \\
\cdot \\
\cdot \\
a_{p}
\end{array}\right) \text { dan } b=\left(\begin{array}{l}
b_{1} \\
b_{2} \\
\cdot \\
\cdot \\
\cdot \\
b_{p}
\end{array}\right)
$$

dimana $b_{1}+b_{2}+\ldots+b_{t}=0$, sedangkan matriks rata-rata

$$
=\mu_{\mathrm{j}}=\left(\begin{array}{l}
\mu_{j 1} \\
\mu_{j 2} \\
\cdot \\
\cdot \\
\cdot \\
\mu_{j p}
\end{array}\right) \operatorname{dan} W=\sum_{j=1}^{t} a^{\prime} \mu_{j} b_{j}
$$

maka interval kepercayaan 1- $\alpha$ untuk W adalah interval dimana batas-batas adalah sebagai berikut :

Batas kiri $=\sum_{j=1}^{t} a^{\prime} x_{. j} b_{j}-\left[\left(\sum_{j=1}^{t} \frac{b_{j}^{2}}{n_{j}} a^{\prime} J K(K) a\left(\frac{x_{\alpha}}{1-x_{\alpha}}\right)\right]^{3}\right.$

Batas kiri $=\sum_{j=1}^{t} a^{\prime} x_{. j} b_{j}+\left[\left(\sum_{j=1}^{t} \frac{b_{j}^{2}}{n_{j}} a^{\prime} J K(K) a\left(\frac{x_{\alpha}}{1-x_{\alpha}}\right)\right]^{3}\right.$

dimana $\mathrm{x}_{\alpha}$ adalah nilai yang diperoleh dari tabel dengan $\mathrm{P}_{\mathrm{O}}=$ banyaknya variabel yang diukur, $\mathrm{m}_{\mathrm{O}}=$ derajat kebebasan untuk Perlakuan dan $\mathrm{n}=$ derajat kebebasan untuk galat.

Untuk $\mathrm{P}_{\mathrm{O}}=1$, terdapat $\frac{\mathrm{x}_{\alpha}}{1-\mathrm{x}_{\alpha}}=\frac{\mathrm{m}_{\mathrm{O}}}{\mathrm{n}} \mathrm{F}_{\alpha ;\left(\mathrm{m}_{\mathrm{o}} ; \mathrm{n}\right)}$ 
Dimisalkan bahwa $k=\mathrm{C}_{2}^{\mathrm{t}}$, banyaknya kombinasi 2 dari t, dan jika hanya kontras-kontras yang memuat dua rata-rata populasi yang digunakan, maka banyaknya kontras adalah $\mathrm{k}$ dengan batas intervel keyakinan adalah

$$
\sum \quad a^{\prime} x_{. j} b_{j} \pm t^{2} \frac{\alpha}{2 k} ; n-t \sqrt{\left(\sum \frac{b_{j}^{2}}{n_{j}}\right) a^{\prime} s a} \text {, dimana }
$$

$\mathrm{S}$ adalah matriks varians-kovarians sampel.

Jika interval keyakinan untuk perbedaan sebuah pasangan rata-rata tidak memuat bilangan 0 , maka perbedaan itu signifikan pada taraf signifikansi $\alpha$ yang diberikan. Untuk menjelelaskan bagian ini perhatikan contoh berikut

Jika dari data di atas dicari interval keyakinan untuk

$$
\begin{aligned}
& a=\left(\begin{array}{l}
1 \\
0
\end{array}\right) \text { atau } a=\left(\begin{array}{l}
0 \\
1
\end{array}\right) \text { dan untuk } b=\left(\begin{array}{c}
1 \\
-1 \\
0 \\
0
\end{array}\right) \text { atau } \\
& b=\left(\begin{array}{c}
1 \\
0 \\
-1 \\
0
\end{array}\right) \text { atau } b=\left(\begin{array}{c}
1 \\
0 \\
0 \\
-1
\end{array}\right) \text { atau } b=\left(\begin{array}{c}
0 \\
1 \\
-1 \\
0
\end{array}\right) \text { maka }
\end{aligned}
$$

didapatkan hasil sebagai berikut

Tabel 4. Interval Keyakinan Untuk Selisih Rata-rata

\begin{tabular}{ccccl}
\hline$a^{\prime}$ & b' & Var & Kontras & $\begin{array}{c}\text { Interval } \\
\text { Keyakinan }\end{array}$ \\
\hline$(1,0)$ & $(1,-1,0,0)$ & $\mathrm{X}$ & $\mu_{11}-\mu_{21}$ & $(0,99 ; 14,61)$ \\
$(1,0)$ & $(1,0,-1,0)$ & $\mathrm{X}_{1}$ & $\mu_{11}-\mu_{31}$ & $(-3,61 ; 10,01)$ \\
$(1,0)$ & $(1,0,0,-1)$ & $\mathrm{X}_{1}$ & $\mu_{11}-\mu_{41}$ & $(-1,41 ; 12,21)$ \\
$(1,0)$ & $(0,1,-1,0)$ & $\mathrm{X}_{1}$ & $\mu_{12}-\mu_{31}$ & $(-11,41 ; 2,21)$ \\
$(1,0)$ & $(0,1,0-1)$ & $\mathrm{X}_{1}$ & $\mu_{21}-\mu_{41}$ & $(-9,21 ; 4,41)$ \\
$(1,0)$ & $(0,0,1,-1)$ & $\mathrm{X}_{2}$ & $\mu_{31}-\mu_{41}$ & $(-2,1 ; 2,5)$ \\
$(1,0)$ & $(1,-1,0,0)$ & $\mathrm{X}_{2}$ & $\mu_{12}-\mu_{22}$ & $(-2,5 ; 2.1)$ \\
$(1,0)$ & $(1,0,-1,0)$ & $\mathrm{X}_{2}$ & $\mu_{12}-\mu_{32}$ & $(-1,1 ; 3,5)$ \\
$(1,0)$ & $(1,0,0,-1)$ & $\mathrm{X}_{2}$ & $\mu_{12}-\mu_{42}$ & $(-2,7 ; 1,9)$ \\
$(1,0)$ & $(0,1,-1,0)$ & $\mathrm{X}_{2}$ & $\mu_{22}-\mu_{32}$ & $(-2,7 ; 1,9)$ \\
$(1,0)$ & $(0,1,0-1)$ & $\mathrm{X}_{2}$ & $\mu_{22}-\mu_{42}$ & $(-1,3 ; 3,3)$ \\
$(1,0)$ & $(0,0,1,-1)$ & $\mathrm{X}_{2}$ & $\mu_{32}-\mu_{42}$ & $(-0,9 ; 3,7)$ \\
\hline
\end{tabular}

Berdasarkan tabel diatas maka dapat disimpulkan bahwa pada taraf signifikansi $5 \%$, perbedaan tinggi batang antara varietas $V_{1}$ dan varietas $V_{2}$ adalah signifikan.

\section{KESIMPULAN}

Pada Analisis Varians Multivariat ada beberapa statistik uji yang dapat digunakan untuk membuat keputusan terhadap hipotesis yang diajukan. Pembuktian hipotesis yang diajukan didasarkan juga pada rancangan eksperimen yang digunakan. Ada kemiripan penggunaan analisis varians pada kondisi univariat dengan analisis varians multivariat pada rancangan acak lengkap. Salah satu statistik uji yang biasa digunakan adalah statistik Wilks lambda.

Kesulitan yang timbul adalah bagaimana menata serta kemudian melakukan analisis terhadap data hasil pengukuran yang telah dilakukan. Penggunaan konsep matriks khususnya konsep varian kovarians menjadi pilihan untuk menyelesaikan analisis ini, walaupun dewasa ini tersedia komputer dengan perangkat analisis data yang sangat familiar untuk digunakan

\section{DAFTAR PUSTAKA}

Bain. I, J. dan Engelhardt, M., (1992), Introduction To Probability And Mathematical Statistics, $2^{\text {nd }}$ ed., Duxbury Press, California.

Dudewicz, E. J. dan Mishra, S. N., (1988), Modern Mathematical Statistics, John Wiley \& Sons, New York.

Hogg. R. V. dan Craig, A. T., (1995), Introduction to Mathematical Statistics,Fifth Ed., Prentice-Hall, Inc, New Jersey.

Dillon, W.R and M. Goldstein. 1984. Multivariate Analysis Methods and Aplications. Toronto : Joohn Wiley \& Sons.

Kuntoro, 2000, Kajian Model Lisrel. Forum Ilmu Kesehatan Masyarakat

`Tahun ke XIX No. Fakultas Ilmu Keshatan Masyarakat Unair.

Morrison, D.F. 1988. Multivariate Statistical Analysis. Auckland : McGraw-Hill, Inc

Solimun, 2002. Multivariate Analysis : Structural Equation Modelling(SEM) Lisrel dan Amos. Penerbit Univesitas Negeri Malang. 